\title{
Sputtered iridium oxide films (SIROFs) for neural stimulation electrodes
}

\author{
Stuart F. Cogan ${ }^{1}$, Julia Ehrlich1, Timothy D. Plante ${ }^{1}$, Anton Smirnov1 ${ }^{1}$ Douglas B. Shire ${ }^{2,3}$, \\ Marcus Gingerich ${ }^{2,3}$, and Joseph F. Rizzo ${ }^{4,5}$ \\ ${ }^{1}$ EIC Laboratories, Inc. 111 Downey St. Norwood, MA 02062 \\ 2Department of Veterans Affairs, Center for Innovative Visual Rehabilitation, 119 Phillips Hall, \\ Cornell University, Ithaca, NY 14853 \\ ${ }^{3}$ Cornell NanoScale Science and Technology Facility, Ithaca NY 14853 \\ ${ }^{4}$ Center for Innovative Visual Rehabilitation, Department of Veterans Affairs, Boston, MA \\ ${ }^{5}$ Massachusetts Eye and Ear Infirmary, Boston, MA
}

\begin{abstract}
Sputtered iridium oxide films (SIROFs) deposited by DC reactive sputtering from an iridium metal target have been characterized in vitro for their potential as neural recording and stimulation electrodes. SIROFs were deposited over gold metallization on flexible multielectrode arrays fabricated on thin $(15 \mu \mathrm{m})$ polyimide substrates. SIROF thickness and electrode areas of 200 $1300 \mathrm{~nm}$ and $1960-125600 \mu \mathrm{m}^{2}$, respectively, were investigated. The charge-injection capacities of the SIROFs were evaluated in an inorganic interstitial fluid model in response to chargebalanced, cathodal-first current pulses. Charge injection capacities were measured as a function of cathodal pulse width $(0.2-1 \mathrm{~ms})$ and potential bias in the interpulse period $(0.0$ to $0.7 \mathrm{~V} \mathrm{vs}$. Ag) $\mathrm{AgCl}$ ). Depending on the pulse parameters and electrode area, charge-injection capacities ranged from $1-9 \mathrm{mC} / \mathrm{cm}^{2}$, comparable with activated iridium oxide films (AIROFs) pulsed under similar conditions. Other parameters relevant to the use of SIROF on nerve electrodes, including the thickness dependence of impedance $\left(0.05-10^{5} \mathrm{~Hz}\right)$ and the current necessary to maintain a bias in the interpulse region were also determined.
\end{abstract}

\section{Keywords}

neural stimulation; neural recording; microelectrode; iridium oxide; sputtering

\section{INTRODUCTION}

Emerging prostheses and therapies involving neural stimulation electrodes implanted in the central or peripheral nervous system will require charge-injection levels that challenge the capabilities of noble metals.1,2 Reported electrical thresholds for eliciting a neuronal response in brain structures with indwelling cortical microelectrodes are about $1 \mathrm{nC}$ per phase, with functional thresholds still uncertain.3,4 Typically, intracortical electrodes have an active geometric area of about $1000 \mu \mathrm{m}^{2}$, resulting in a minimum charge density of 0.1 $\mathrm{mC} / \mathrm{cm}^{2}$. For deep brain stimulation with microelectrodes, charge densities on the order of $0.4 \mathrm{mC} / \mathrm{cm}^{2}$ are expected.5 Stimulation studies with retinal surface electrodes have identified perceptual thresholds in humans that vary from $24 \mathrm{nC}$ to $>1 \mu \mathrm{C}$ per phase.6,7,8 
Even at the lower threshold values, charge densities over $1 \mathrm{mC} / \mathrm{cm}^{2}$ may be necessary to obtain high resolution in visual prostheses that stimulate the retina.9 For charge-injection densities over $\sim 0.2 \mathrm{mC} / \mathrm{cm}^{2}$, based on geometric surface area, low impedance coatings of activated iridium oxide films (AIROFs) or high-porosity (fractal) titanium nitride (f-TiN) are usually employed.10,11 Iridium oxide films inject charge via reversible reduction and oxidation between $\mathrm{Ir}^{3+} / \mathrm{Ir}^{4+}$ valence states within the oxide film, while $\mathrm{f}-\mathrm{TiN}$ is a capacitive electrode that operates by charging and discharging the double-layer at the TiN-electrolyte interface. Other materials that are potentially capable of high levels of charge injection, such as carbon nanotubes and conductive polymers, are also being investigated, but there is presently little in vivo experience with these materials as stimulation electrodes.12,13 More recent efforts to employ moderately porous films of platinum that can inject charge at $>1$ $\mathrm{mC} / \mathrm{cm}^{2}$ have also been reported.14

Studies of AIROF as a charge-injection coating were first reported in 1983 by Robblee et al . 10 Since that time, AIROF has been used for in vivo studies assessing the safety of intracortical stimulation, 3,4 and in an investigational prosthesis for vision employing intracortical microelectrodes.15,16 For applications in neural prostheses, AIROF is formed from iridium metal by electrochemical potential cycling in an aqueous electrolyte, usually an acid (e.g. $1 \mathrm{~N} \mathrm{H}_{2} \mathrm{SO}_{4}$ ) or well-buffered physiological saline at $\mathrm{pH}$ 7.4.2,17 Other methods of forming iridium oxide, notably electrodeposition and thermal decomposition of iridium salt solutions, have also been reported.18,19 Judging by the similarity between the electrochemical response of AIROF and the electrodeposited and thermally formed iridium oxides, these iridium oxides must have a similar composition and structure. AIROF formed by potential cycling is a hydrated oxide with a density of less than $20 \%$ of that of crystalline $\mathrm{IrO}_{2} .20$

Iridium oxide films can also be formed by reactive sputtering from an iridium metal target in an oxidizing plasma. Sputtered iridium oxide films (SIROFs) have been investigated for optical switching applications, 21 and more recently as coatings for neural stimulation electrodes. Klein et al investigated the relationship between sputter deposition conditions and the charge capacity and surface morphology of SIROF.22,23 Aurian-Blajeni et al proposed a bilayer structure for SIROF comprised of an inner layer with a structure influenced by the substrate and an outer layer with properties determined solely by the deposition conditions. 24 In these early studies, no charge-injection limits for current pulsing were reported, although extensive control of film morphology was demonstrated. More recently, charge-injection capacities of $0.1 \mathrm{mC} / \mathrm{cm}^{2}$ and higher were reported by Slavcheva et al 25 for $200 \mathrm{~nm}$ thick SIROF using relatively long $10 \mathrm{~ms}$ pulses. Cogan et al 26 reported charge-injection limits of $0.75 \mathrm{mC} / \mathrm{cm}^{2}$ using $0.75 \mathrm{~ms}$ pulses with DC-sputtered SIROF on $0.05 \mathrm{~cm}^{2}$ electrodes, and Wessling et al27 evaluated the effects of deposition conditions on the morphology of RF-sputtered SIROF intended for neural stimulation applications. Films of SIROF have also been used on flexible multielectrode arrays employing neurotrophineluting hydrogel coatings, with the objective of reducing functional electrical thresholds in neural prostheses. 28

In the present work, we have conducted an in vitro investigation of the charge-injection properties of SIROF deposited on multielectrode polyimide arrays as part of an effort to develop a retinal prosthesis for vision loss associated with retinal degeneration.6 The effect of SIROF thickness and electrode size on the electrochemical behavior and charge-injection capabilities were investigated. The advantage of positively biasing the potential of the SIROF during current pulsing, similar to the strategy employed with AIROF, was also demonstrated. The SIROFs exhibited charge-injection capabilities similar to those of AIROF or electrodeposited iridium oxide and offer an alternative to those materials, as well as Pt or f-TiN, for neural stimulation. 


\section{EXPERIMENTAL}

\section{Multielectrode Arrays}

For charge-injection limit and area effect measurements, multielectrode arrays (MEAs) were fabricated with 28 circular electrodes arranged in four clusters of seven, with each cluster containing one electrode with a diameter of $50 \mu \mathrm{m}, 100 \mu \mathrm{m}, 200 \mu \mathrm{m}, 300 \mu \mathrm{m}, 400 \mu \mathrm{m}, 600$ $\mu \mathrm{m}$ and $800 \mu \mathrm{m}$. A scanning electron micrograph of a cluster is shown in Fig. 1. The array design includes a large, rectangular return electrode that surrounds the seven stimulation electrodes, although the return electrode on the array was not used in this study. Electrodes with diameters of $50 \mu \mathrm{m}$ through $400 \mu \mathrm{m}$ were included in the analysis, providing electrodes with geometric surface areas (GSAs) of $1960 \mu \mathrm{m}^{2}, 7850 \mu \mathrm{m}^{2}, 31400 \mu \mathrm{m}^{2}, 70650 \mu \mathrm{m}^{2}$, and $125600 \mu \mathrm{m}^{2}$, respectively. The two largest electrode sites were not evaluated because their size is too large to be useful in a high-resolution, retinal prosthesis.9

The MEAs were fabricated by spinning a $12 \mu \mathrm{m}$ thick base coating onto a $100 \mathrm{~mm}$-diameter silicon wafer using HD Microsystems PI-2611 polyimide, which was subsequently cured in a $\mathrm{N}_{2}$-purged vacuum oven at $350^{\circ} \mathrm{C}$. A 3-layer metallization, comprised of two titanium adhesion layers and a gold conductor (Ti/Au/Ti), was deposited on the polyimide by physical vapor deposition and patterned using a lift-off resist process. The Ti and Au films were $50 \mathrm{~nm}$ and $1.5 \mu \mathrm{m}$ thick, respectively. A $3 \mu \mathrm{m}$-thick polyimide overlayer was then spun onto the metallized polyimide and cured at $350^{\circ} \mathrm{C}$. Electrode sites and contact pads were formed by patterning the wafer with photoresist and exposing the underlying metallization by $\mathrm{O}_{2}$ reactive ion etching (RIE) through the polyimide overlayer. The wafer was then re-patterned with photoresist to expose only the electrode sites, which were coated with SIROF by reactive DC sputtering from an iridium metal target using deposition conditions described previously.29 A reactive gas mixture of $\mathrm{Ar}, \mathrm{O}_{2}$ and $\mathrm{H}_{2}$ was employed to produce SIROF with a mixed $\mathrm{Ir}^{3+} / \mathrm{Ir}^{4+}$ reduction-oxidation state. The SIROF extends slightly onto the polyimide lip at the electrode circumference to prevent underlying metallization at the charge-injection site from being exposed directly to the test electrolytes. The degree of extension is independent of film thickness. The wafers were again patterned with photoresist, and $\mathrm{O}_{2}$ RIE used to form the perimeter of each individual array by etching through the combined $15-\mu \mathrm{m}$ thickness of the polyimide layers. After soaking in water, the individual arrays are readily removed from the silicon wafers. The thickness of the SIROFs investigated ranged from $200 \mathrm{~nm}$ to $1300 \mathrm{~nm}$. The as-deposited SIROF was characterized by scanning electron microscopy (SEM) using an FEI Quanta 200 and film thickness was determined from measurements of SIROFs on glass witness samples using a Dektak surface profilometer.

\section{Electrochemical Measurements}

Electrical contact to the arrays was made with a custom-built clamp that held the contact pads at the proximal end of the array against raised gold bumps on a circuit board. A ribbon cable connector mounted on the circuit board then connected to external instrumentation. The SIROFs were characterized electrochemically by cyclic voltammetry (CV) and electrochemical impedance spectroscopy (EIS). Two electrolytes were employed for the study: an Ar-deaerated, phosphate-buffered saline (PBS) having a composition of $126 \mathrm{mM}$ $\mathrm{NaCl}, 22 \mathrm{mM} \mathrm{NaH} \mathrm{PO}_{4}-7 \mathrm{H}_{2} \mathrm{O}$ and $81 \mathrm{mM} \mathrm{Na}_{2} \mathrm{HPO}_{4}-\mathrm{H}_{2} \mathrm{O}$ at $\mathrm{pH}$ 7.2-7.4, and an inorganic model of interstitial fluid (model-ISF) having a composition of $\mathrm{NaCl} 110 \mathrm{mM}, \mathrm{NaHCO}_{3} 28$ $\mathrm{mM}, \mathrm{KHCO}_{3} 7.5 \mathrm{mM}, \mathrm{Na}_{2} \mathrm{HPO}_{4}-7 \mathrm{H}_{2} \mathrm{O} 2 \mathrm{mM}$, and $0.5 \mathrm{mM}$ each of $\mathrm{NaH}_{2} \mathrm{PO}_{4}-\mathrm{H}_{2} \mathrm{O}$, $\mathrm{MgSO}_{4}, \mathrm{MgCl}_{2}$, and $\mathrm{CaCl}_{2} .30$ For the model-ISF, a $\mathrm{pH}$ of 7.4 was maintained by a gentle flow of $5 \% \mathrm{CO}_{2} / 6 \% \mathrm{O}_{2} / 89 \% \mathrm{~N}_{2}$ gas through the electrolyte. Measurements in PBS were made at room temperature, while measurements in model-ISF were made at $37^{\circ} \mathrm{C}$. All electrochemical measurements were made in a three-electrode cell using a large-area 
platinum counterelectrode and a $\mathrm{Ag} \mid \mathrm{AgCl}(3 \mathrm{M} \mathrm{KCl})$ reference electrode. All potentials are reported with respect to $\mathrm{Ag} \mid \mathrm{AgCl}$.

Slow sweep rate $\mathrm{CV}$ measurements $(50 \mathrm{mV} / \mathrm{s})$, between potential limits of $-0.6 \mathrm{~V}$ and 0.8 $\mathrm{V}$, in PBS were used to calculate cathodal charge storage capacities $\left(\mathrm{CSC}_{\mathrm{c}}\right)$. The $\mathrm{CSC}_{\mathrm{c}}$ estimates the total amount of iridium oxide deposited on the substrate and is determined from the time integral of the negative current during a full $\mathrm{CV}$ cycle at a sweep rate of 50 $\mathrm{mV} / \mathrm{s}^{2}{ }^{2}$ The EIS measurements were made in model-ISF over a $0.05-10^{5} \mathrm{~Hz}$ frequency range using a $10 \mathrm{mV}$ rms sinusoidal excitation voltage about a fixed potential between -0.6 $\mathrm{V}$ and $0.8 \mathrm{~V}$. The CV and EIS measurements were made with Gamry PC4 or PC3 potentiostats and vendor supplied software. Prior to electrochemical measurements all SIROF films were subjected to CV cycling in PBS to rehydrate the films following the final steps in the array fabrication process. Typically, a stable CV response was obtained after three hours, equal to 193 cycles.

Charge-injection limits were determined from potential transients measured during current pulsing in model-ISF at $37^{\circ} \mathrm{C}$. Two current waveforms employing different chargebalancing strategies were used. With both waveforms, the microelectrode potential in the interpulse period was positively biased relative to the $\mathrm{Ag} \mid \mathrm{AgCl}$ reference electrode. With one waveform, the current pulses were delivered as charge-balanced, biphasic pairs at a frequency of 50 pulses/s, with the leading phase always cathodal. The pulse pairs were asymmetric with the cathodal phase delivered at a higher current and shorter pulsewidth than the anodal phase. The rationale for employing asymmetric current pulsing when using a positive bias with iridium oxide has been detailed previously.30 Asymmetries in the waveforms, defined as the ratio of the anodal-to-cathodal pulsewidth $\left(t_{\mathrm{a}}: \mathrm{t}_{\mathrm{c}}\right)$, from 1:1 to $8: 1$ were investigated. The cathodal and anodal phases were separated by a $20 \mu$ s interphase delay $\left(t_{d}\right)$, during which the applied current was zero. The maximum cathodally driven electrochemical potential excursion $\left(\mathrm{E}_{\mathrm{mc}}\right)$ was taken as the voltage recorded in the interphase period, approximately $10 \mu$ s after the end of the cathodal pulse. Similarly, the maximum anodally driven potential excursion $\left(\mathrm{E}_{\mathrm{ma}}\right)$ was taken as the voltage $10 \mu \mathrm{s}$ after the end of the anodal pulse. The advantage of determining $\mathrm{E}_{\mathrm{mc}}$ and $\mathrm{E}_{\mathrm{ma}}$ in this manner is the absence of an ohmic contribution to the measured potential.32 An example of an asymmetric current waveform and resulting voltage transient is shown in Fig. 2. The maximum charge that could be injected with the SIROF was defined as that which polarized the electrode to either $\mathrm{E}_{\mathrm{mc}}=-0.6 \mathrm{~V}$ or $\mathrm{E}_{\mathrm{ma}}=+0.8 \mathrm{~V}$, whichever potential was reached first. The potential transients were recorded after a steady-state response was obtained, usually within $30 \mathrm{~s}$ after the pulsing was initiated. Interpulse potential bias levels $\left(\mathrm{E}_{\mathrm{ipp}}\right)$ from 0.0 to $0.7 \mathrm{~V}$ were investigated.

In the second strategy, monophasic cathodal current pulses were delivered with a positively biased electrode using the compliance-limited pulsing method proposed by Troyk et al.32 Charge-balance is obtained by reestablishing the bias potential in the interpulse period using an anodic recharge current that is sufficient to establish the bias within a few milliseconds of the cathodal pulse. The stimulator is designed to limit the recharge current so that the microelectrode cannot be polarized more positively than the $0.8 \mathrm{~V}$ water oxidation limit observed with AIROF or Pt electrodes. It is also possible with the compliance limited strategy to avoid polarizing the electrode more negative than a preset negative driving voltage, such as the reduction potential for water, although this aspect of compliance-limited charge delivery was not employed in the present study. An example of the voltage and current waveforms for the compliance-limited pulsing is shown in Fig. 3 for a $300 \mathrm{~nm}$ SIROF $\left(\mathrm{GSA}=1960 \mu \mathrm{m}^{2}\right.$ ) pulsed at $\mathrm{I}_{\mathrm{c}}=248 \mu \mathrm{A}, \mathrm{t}_{\mathrm{c}}=0.4 \mathrm{~ms}$, and $\mathrm{t}_{\mathrm{d}}=0.1 \mathrm{~ms}$. The $\mathrm{E}_{\mathrm{mc}}$ is -0.6 $\mathrm{V}$, resulting in a charge-injection capacity of $99 \mathrm{nC} /$ phase $\left(5.1 \mathrm{mC} / \mathrm{cm}^{2}\right)$ for this electrode. The anodic recharge current $\left(\mathrm{I}_{\mathrm{a}}\right)$ peaked at $72 \mu \mathrm{A}$ and is shown decreasing in magnitude as 
the electrode voltage approaches the $0.6 \mathrm{~V} \mathrm{E}_{\mathrm{ipp}}$. The monophasic waveform was used to measure the charge-injection capacity of SIROF at three thickness levels $(240 \mathrm{~nm}, 500 \mathrm{~nm}$, $770 \mathrm{~nm})$ and at two pulse widths $(0.4 \mathrm{~ms}$ and $1 \mathrm{~ms})$. For the monophasic pulsing the criterion for maximum charge-injection limit was that the electrode should not be polarized negative of the water reduction potential $(-0.6 \mathrm{~V})$.

The current required to sustain a positive bias in the absence of pulsing was measured chronoamperometrically by holding the electrode at a fixed potential and recording the current response over $1500 \mathrm{~s}$ at a measurement frequency of $1 \mathrm{~Hz}$. The steady state current was taken as the average of the last 300 data points in the record. The bias current was measured at potentials from $0 \mathrm{~V}$ to $0.7 \mathrm{~V}$ in $0.1 \mathrm{~V}$ increments.

\section{RESULTS}

\section{SIROF Surface Morphology and Charge Storage Capacity}

SIROF morphology is shown in Fig. 4 for films with a thickness of $240 \mathrm{~nm}, 500 \mathrm{~nm}$, and $770 \mathrm{~nm}$. The $770 \mathrm{~nm}$ SIROF is comprised of densely packed nodules that are approximately circular with a diameter of $200-400 \mathrm{~nm}$. For the $500 \mathrm{~nm}$ SIROF, the nodular surface is less developed but still apparent, while for the $240 \mathrm{~nm}$ SIROF the surface morphology is barely observable. Representative CVs in PBS for these SIROFs are shown in Fig. 5. Averaged over one array, the $\mathrm{CSC}_{\mathrm{c}}$ of the $50 \mu \mathrm{m}$ diameter SIROF sites increased with thickness from $78 \pm 2 \mathrm{mC} / \mathrm{cm}^{2}(\mathrm{n}=4)$ at $240 \mathrm{~nm}$ and $133 \pm 6 \mathrm{mC} / \mathrm{cm}^{2}(\mathrm{n}=4)$ at $500 \mathrm{~nm}$, to $194 \pm 2 \mathrm{mC} / \mathrm{cm}^{2}$ $(\mathrm{n}=3)$ at $770 \mathrm{~nm} ; \mathrm{CSC}_{\mathrm{c}}$ was nearly linear with thickness over this range. As observed with AIROF, 32 the $\mathrm{CSC}_{\mathrm{c}}$ measured in model-ISF at room temperature is less than that measured in PBS, being about $20 \%$ less for the $240 \mathrm{~nm}$ SIROF. The lower $\mathrm{CSC}_{\mathrm{c}}$ is due to the reduced buffering capacity of the carbonate-based model-ISF compared with the phosphate buffer in PBS, which is also present at much higher concentrations than is found physiologically.

Qualitatively, SIROF exhibits good adhesion. Coatings ranging in thickness from 200 $1300 \mathrm{~nm}$ deposited with a titanium adhesion layer on glass slides remained adherent when challenged by snap-pull and slow-pull tape tests. For all SIROF thickness levels, the tape adhesive remained as residue on the film, a phenomenon often observed when tape testing porous but adherent films. Thin SIROF ([300 nm) exhibits good abrasion on glass substrates, although thicker films are marred and can be partially removed when rubbed with a pencil eraser.

\section{Potential Limits for SIROF Stability}

SIROF electrodes with a diameter of $50 \mu \mathrm{m}$ were investigated by cyclic voltammetry in model-ISF at a sweep rate of $50 \mathrm{mV} / \mathrm{s}^{1}$. The positive and negative limits of the triangular potential waveform were expanded in $50 \mathrm{mV}$ increments from $-0.6 \mathrm{~V}$ and $0.8 \mathrm{~V}$ in the negative and positive directions, respectively, until evidence of water electrolysis or other non-reversible processes at each limit was observed. At a potential of $1.05 \mathrm{~V}$, a sharp increase in anodic current occurs due to the onset of water oxidation. Water reduction was observed at a potential of $-1.05 \mathrm{~V}$, and was accompanied by SIROF delamination from the underlying metallization after several $\mathrm{CV}$ cycles to this negative limit. To avoid delamination in subsequent studies, the maximum negative potential was limited to $-0.9 \mathrm{~V}$. Repetitive cycling between limits of -0.9 and $1.05 \mathrm{~V}$ produced some changes in the SIROF CVs as shown by the comparison in Fig. 6 using a $1300 \mathrm{~nm}$ thick, $50 \mu \mathrm{m}$ diameter SIROF electrode of the responses before and after 393 cycles between these voltage limits at a rate of $50 \mathrm{mV} / \mathrm{s}$. At potentials more negative than about $-0.25 \mathrm{~V}$, there is a loss of charge capacity, as indicated by a decrease in cathodic current (hatched area, Fig. 6). This loss of cathodic charge capacity is reflected in an overall decease in anodic current, which occurs 
broadly over a -0.6 to $1.0 \mathrm{~V}$ potential range on the positive scan. The principal reduction and oxidation peaks, at $-0.2 \mathrm{~V}$ and $0.5 \mathrm{~V}$, respectively, were also more pronounced after cycling. There was no visible indication of delamination or the emergence of new peaks in the CV response, such as are observed with over-pulsed AIROF,17 that would indicate degradation of the SIROF. Since previous assessments of the charge-injection properties of iridium oxide and platinum-based electrodes have used $-0.6 \mathrm{~V}$ and $0.8 \mathrm{~V}$ as potential limits for cyclic voltammetry and as allowable maximum potential excursions during current pulsing, CVs over this more limited potential range were also evaluated. A comparison of the SIROF CV response between $-0.6 \mathrm{~V}$ and $0.8 \mathrm{~V}$, taken before and after the 393 cycle $-0.90 / 1.05 \mathrm{~V}$ challenge, is shown in Fig. 7. Similar to the CVs at the more expanded potential range, the SIROF exhibits a reduced cathodic charge capacity at negative potentials and more pronounced $\mathrm{Ir}^{3+} / \mathrm{Ir}^{4+}$ redox peaks after cycling. The $\mathrm{CSC}_{\mathrm{c}}$ of the SIROF at the $-0.6 / 0.8 \mathrm{~V}$ limits decreased modestly from $177 \mathrm{mC} / \mathrm{cm}^{2}$ to $169 \mathrm{mC} / \mathrm{cm}^{2}$ after the 393 cycles. The magnitude of the $\mathrm{CSC}_{\mathrm{c}}$ is noteworthy, being considerably higher than that typically obtained with AIROF charge-injection coatings, which are prone to delamination at $\mathrm{CSC}_{\mathrm{c}}$ levels much above $80 \mathrm{mC} / \mathrm{cm}^{2}$. Following the 393 cycle challenge, the SIROF was cycled for an additional 100 cycles between limits of $-0.6 \mathrm{~V}$ and $0.8 \mathrm{~V}$ without changes in the $\mathrm{CV}$ response from that shown in Fig. 7. The same potential dependence for water electrolysis and SIROF delamination was also observed for $400 \mathrm{~nm}$ thick films with diameters of $50 \mu \mathrm{m}$ and $400 \mu \mathrm{m}$.

\section{SIROF Impedance}

The impedance modulus of SIROF in model-ISF is shown in Fig. 8 as a function of film thickness, with an uncoated gold site included for comparison. Even for the $200 \mathrm{~nm}$ SIROF, the impedance compared with the uncoated electrode site is reduced by more than a factor of 10 , over the frequency range typically used for neural recording $\left(10^{2}-10^{4} \mathrm{~Hz}\right)$. Increasing the SIROF thickness to $1300 \mathrm{~nm}$ results in a further decrease in impedance, most notably at frequencies below $100 \mathrm{~Hz}$. The SIROF impedance response is typical of that observed with other iridium oxides or high surface area electrodes, such as f-TiN, exhibiting resistive behavior dominated by electrolyte conductivity at high frequencies and capacitive-like behavior at low frequencies were charge transfer reactions dominate.

\section{Charge-injection Limits}

The charge-injection capacity of the SIROF was measured in model-ISF $\left(37^{\circ} \mathrm{C}\right)$ as a function of bias voltage, pulse width, waveform asymmetry, SIROF thickness, and electrode area. The conservative potential limits of $-0.6 \mathrm{~V}$ and $0.8 \mathrm{~V}$ were used to define the chargeinjection capacity and allow direct comparison with the reported charge-injection capacities of AIROF and PtIr metal electrodes.2,34,35

Bias and Waveform Asymmetry-The charge-injection limits of a $300 \mathrm{~nm}$ thick, 50 $\mu \mathrm{m}$ diameter SIROF electrode are shown in Fig. 9 as a function of bias and waveform asymmetry for biphasic pulses with a 0.4 ms leading cathodal phase and pulse frequency of $50 \mathrm{~Hz}$. These are representative data from a single electrode. The maximum charge-injection capacity for this electrode is $4.7 \mathrm{mC} / \mathrm{cm}^{2}$ obtained at a $0.6 \mathrm{~V}$ bias and waveform asymmetry of $4: 1$. The charge was cathodally limited, meaning that the $-0.6 \mathrm{~V}$ negative limit was reached before the $0.8 \mathrm{~V}$ positive limit. Filled and open symbols in Fig. 9 represent cathodally and anodally limited charge-injection limits, respectively. The dependence on interpulse bias and waveform asymmetry is similar to that obtained with AIROF, which also exhibits a maximum charge-injection capacity at a $0.6 \mathrm{~V}$ bias. 31 The SIROF chargeinjection limits were notably less sensitive to interpulse bias than those of AIROF, which decrease to $<10 \%$ of the maximum charge-injection capacity as the bias is reduced from 0.6 $\mathrm{V}$ to $0 \mathrm{~V}$. For SIROF, the charge capacity shows a $50 \%$ decrease over the same bias range. 
Pulse Width-The dependence of SIROF charge-injection capacity on pulse width for a $300 \mathrm{~nm}$ thick, $50 \mu \mathrm{m}$ diameter electrode is shown in Fig. 10. Charge-injection capacities of AIROF and PtIr microelectrodes with a similar area from Cogan et al 2 are included for comparison. Each SIROF data point is the mean of four 50- $\mu \mathrm{m}$ diameter sites from one array and the error bars are the standard deviation of the mean. As expected, the SIROF chargeinjection capacity increases monotonically from $3.54 \mathrm{mC} / \mathrm{cm}^{2}$ to $7.64 \mathrm{mC} / \mathrm{cm}^{2}$ as the pulse width is increased from $0.2 \mathrm{~ms}$ to $1.0 \mathrm{~ms}$. The same pulse width dependence was observed for all SIROF thickness levels investigated.

SIROF Thickness-SIROF charge-injection capacity did not vary significantly in a comparison of three film thickness of $240 \mathrm{~nm}(\mathrm{n}=4), 500 \mathrm{~nm}(\mathrm{n}=4)$, and $770 \mathrm{~nm}(\mathrm{n}=3)$ for 50 $\mu \mathrm{m}$ diameter electrodes subjected to $400 \mu$ s pulses at a bias of $0.6 \mathrm{~V}$ vs. $\mathrm{Ag} \mid \mathrm{AgCl}(\mathrm{P}>0.05$, one way ANOVA). Similar results were obtained for these electrodes with $1 \mathrm{~ms}$ pulse widths, although the $500 \mathrm{~nm}$ SIROF exhibited a slightly lower, but statistically significant, $\mathrm{Q}_{\text {inj }}$ than either the $240 \mathrm{~nm}$ or $770 \mathrm{~nm} \operatorname{SIROF}(\mathrm{P}=0.003$, one way ANOVA). For the three pooled thickness levels, the $Q_{\text {inj }}$ for the $0.4 \mathrm{~ms}$ and $1.0 \mathrm{~ms}$ pulse widths was $5.2 \pm 0.3 \mathrm{mC} /$ $\mathrm{cm}^{2}$ and $8.9 \pm 0.6 \mathrm{mC} / \mathrm{cm}^{2}$ (mean \pm s.d.), respectively. The lack of thickness dependence of $\mathrm{Q}_{\text {inj }}$ during current pulsing contrasts with the much lower current density CV measurements, in which $\mathrm{CSC}_{\mathrm{c}}$ exhibits a linear dependence on SIROF thickness.

Electrode Area-The geometry and area of an electrode can affect charge-injection capacity measurements because of the non-uniform current distribution which localizes the charge-injection reactions to the perimeter of the electrode. With short duration current pulses, the central regions of the electrode are underutilized and a lower overall chargeinjection density results. The charge-injection capacity as a function of area is shown in Fig. 11 as an average of five films with a thickness range of 200-1000 nm. For the average response, the charge injection capacity decreased from $4.4 \pm 0.8 \mathrm{mC} / \mathrm{cm}^{2}$ to $1.9 \pm 0.2 \mathrm{mC} / \mathrm{cm}^{2}$ as the electrode area increased from $1960 \mu \mathrm{m}^{2}$ to $125,600 \mu \mathrm{m}^{2}$. The charge per phase is still much higher for the larger area films, increasing from $0.09 \pm 0.02 \mu \mathrm{C} / \mathrm{ph}$ to $2.4 \pm 0.3 \mu \mathrm{C} / \mathrm{ph}$ for the same increase in area. The data are shown averaged over a range of thickness levels to emphasize the dominance of the electrode area dependence over that of the SIROF thickness when measuring $Q_{\text {inj }}$ by voltage transient measurements at least for the thickness range investigated.

\section{Bias Maintenance Current}

Applying a positive bias to increase the cathodal charge-injection capacity of the SIROF requires a sustained DC current in the interpulse period to maintain the iridium oxide at a non-equilibrium potential. The current density is shown in Fig. 12 as a function of bias potential and thickness for $400 \mu \mathrm{m}$ diameter electrodes $(n=4)$. The current density necessary to sustain a bias increases significantly at potentials more positive than $0.4 \mathrm{~V}$ and also increases with SIROF thickness. At a bias of $0.6 \mathrm{~V}$, the current density increases from $0.46 \pm 0.23 \mu \mathrm{A} / \mathrm{cm}^{2}$ to $10.2 \pm 1.7 \mu \mathrm{A} / \mathrm{cm}^{2}$ as SIROF thickness increases from $200 \mathrm{~nm}$ to 1000 $\mathrm{nm}$. The corresponding currents are small, ranging from $0.58 \pm 0.29 \mathrm{nA}(200 \mathrm{~nm})$ to $12.8 \pm 2.1$ $\mathrm{nA}(1000 \mathrm{~nm})$. For a $300 \mathrm{~nm}$ thick, $50 \mu \mathrm{m}$ diameter SIROF electrode, the current density required to sustain a $0.6 \mathrm{~V}$ bias was $2.2 \pm 0.5 \mu \mathrm{A} / \mathrm{cm}^{2}$, with a corresponding current of $0.04 \pm 0.01 \mathrm{nA}$. The nature of the chemical reaction that reduces $\mathrm{Ir}^{4+}$, thus requiring the anodic current to sustain a positive bias, is not clearly understood, but the bias currents increase with increasing buffering capacity of the electrolyte in which they are measured. 


\section{DISCUSSION}

There are some notable differences between SIROF and the more familiar AIROF electrode coatings. Previous reports have identified a $\mathrm{CSC}_{\mathrm{c}}$ limit for AIROF of about $80 \mathrm{mC} / \mathrm{cm}^{2}$ beyond which continued activation of iridium to higher $\mathrm{CSC}_{\mathrm{c}}$ levels results in delamination of the AIROF, presumably due the large volume changes associated with the ingress and egress of counterions and water during the oxidation and reduction of the AIROF while cycling. 34 SIROF coatings, however, have been deposited to a $\mathrm{CSC}_{\mathrm{c}}$ of $180 \mathrm{mC} / \mathrm{cm}^{2}$ and remain stable during $\mathrm{CV}$ cycling between $-0.6 \mathrm{~V}$ and $0.8 \mathrm{~V}(50 \mathrm{mV} / \mathrm{s})$. The ability to employ thicker SIROF films may provide some advantage in reducing electrode impedance for neural recording, as shown in Fig. 8. An optimum SIROF thickness for charge-injection for stimulation was not identified. However, SIROF with a thickness in the 200-1300 nm range provides charge-injection comparable with AIROF and substantially greater than that possible with PtIr or high surface area titanium nitride.2,11 The observation that the chargeinjection capacity of SIROF is independent of thickness for levels greater than $200 \mathrm{~nm}$ is consistent with the charge-injection behavior of AIROF. Measurements by Beebe and Rose, 34 using $0.2 \mathrm{~ms}$ pulses and several different controlled current waveforms, revealed an AIROF charge-injection capacity that was independent of $\mathrm{CSC}_{\mathrm{c}}$ for levels greater than $30-$ $40 \mathrm{mC} / \mathrm{cm}^{2}$. The $\mathrm{CSC}_{\mathrm{c}}$ of the SIROF at all thickness levels in the present study exceeded 50 $\mathrm{mC} / \mathrm{cm}^{2}$.

There is some debate as to the details of the reduction and oxidation reactions occurring in iridium oxide films at near-neutral $\mathrm{pH}$. Electrode reactions that rely on the $\mathrm{H}^{+}$or $\mathrm{OH}^{-}$ion as the counterion for electroneutrality exhibit a $\mathrm{pH}$-dependent potential of $-59 \mathrm{mV} / \mathrm{pH}$-unit for a one-electron reaction, the so-called Nernstian response. In the present study, the equilibrium rest potential of SIROF was investigated in the $\mathrm{pH}$ 6-9 range. A near-Nernstian $\mathrm{pH}$ dependent potential of $-58 \mathrm{mV} / \mathrm{pH}$-unit (95\% conf. int. $-55 /-61, \mathrm{n}=4$ ) was observed, suggesting that either $\mathrm{H}^{+}$or $\mathrm{OH}^{-}$is the predominant counterion in the sputtered film. A similar -55 to $-59 \mathrm{mV} / \mathrm{pH}$-unit response for SIROF has been reported.36,37 Based on mirage detection studies, Bardin et al 37 identified $\mathrm{OH}^{-}$as the counterion over a 3-11 pH range, suggesting a counterion expulsion from SIROF during reduction and counterion insertion during oxidation. In contrast, a super-Nernstian behavior has been recognized with AIROF, which exhibits a -70 to $-90 \mathrm{mV} / \mathrm{pH}$-unit dependence on the potential of the principal $\mathrm{Ir}^{3+} / \mathrm{Ir}^{4+}$ redox reaction.38 AIROF electrodes characterized in the present study for comparison with SIROF, exhibited a $-68 \mathrm{mV} / \mathrm{pH}$-unit (95\% conf. int. $-65 /-71, \mathrm{n}=6$ ) dependency. The super-Nernstian response requires that either counterions besides $\mathrm{H}^{+}$and $\mathrm{OH}^{-}$, or a combination of $\mathrm{H}^{+}$and $\mathrm{OH}^{-}$, are involved in the reduction and oxidation processes. Cations, such as $\mathrm{Li}^{+}$and $\mathrm{Na}^{+}$, as well as small anions have also been identified as co-counterions with $\mathrm{H}^{+}$or $\mathrm{OH}^{-}$in AIROF.38 The difference in $\mathrm{pH}$ response between SIROF and AIROF may be related to the differences in the density of the films. AIROF has a density of $<2 \mathrm{~g} / \mathrm{cm}^{3}$, less than $20 \%$ of the density of crystalline $\operatorname{IrO}_{2}\left(\rho=11.2 \mathrm{~g} / \mathrm{cm}^{3}\right)$, with an open, hydrated nano-porous structure that should be conducive to ion transport. Although the density of the SIROF investigated in the present work was not measured, SIROFs are typically much denser, about $7.8 \mathrm{~g} / \mathrm{cm}^{3}$ when fully hydrated, 21 and consequently we expect ion transport in the SIROF to be less facile, favoring smaller counterions.

\section{CONCLUSIONS}

Thin films of sputtered iridium oxide have charge-injection properties similar to activated iridium oxide, exhibiting a bias-dependent charge-injection capacity of about $5 \mathrm{mC} / \mathrm{cm}^{2}$ using $0.4 \mathrm{~ms}$ cathodal current pulses at a bias of $0.6 \mathrm{~V}(\mathrm{Ag} \mid \mathrm{AgCl})$. Adherent sputtered films with cathodal charge storage capacities over $100 \mathrm{mC} / \mathrm{cm}^{2}$ and film thickness over $1000 \mathrm{~nm}$ can be deposited onto gold substrates without stress-induced delamination. The sputtered 
iridium oxide exhibits a near-Nernstian $59 \mathrm{mV} / \mathrm{pH}$-unit response, suggesting a less complicated single counterion $\left(\mathrm{H}^{+}\right.$or $\left.\mathrm{OH}^{-}\right)$charge-injection reaction rather than the superNernstian response observed with AIROF. The SIROF can be deposited and patterned by conventional sputtering and photolithographic techniques, making it suitable as a low impedance recording or stimulation coating for flexible and rigid planar multielectrode arrays. These in vitro studies have also shown that SIROF is stable under moderately aggressive long-term pulsing in an inorganic model of interstitial fluid at $37^{\circ} \mathrm{C}$. Further work is now required to determine the chronic in vivo properties and stability of SIROF coatings under long-term pulsing conditions, in anticipation of their use in retinal prostheses.

\section{Acknowledgments}

Contract grant sponsor: Department of Veterans Affairs, Rehabilitation Research and Development Service (Grant No. C4266-C)

National Institutes of Health, NHLBI Grant No. 5R44HL071395

\section{REFERENCES}

1. Merrill DR, Bikson M, Jefferys JGR. Electrical stimulation of excitable tissue: design of efficacious and safe protocols. J Neurosci Methods. 2005; 141:171-198. [PubMed: 15661300]

2. Cogan SF, Troyk PR, Ehrlich J, Plante TD. In vitro comparison of the charge-injection limits of activated iridium oxide (AIROF) and platinum-iridium microelectrodes. IEEE Trans Biomed Eng. 2005; 52:612-614.

3. McCreery DB, Agnew WF, Bullara LA. The effects of prolonged intracortical microstimulation on the excitability of pyramidal tract neurons in the cat. Ann Biomed Eng. 2002; 30:107-119. [PubMed: 11874134]

4. McCreery DB, Yuen TGH, Bullara LA. Chronic microstimulation in the feline ventral cochlear nucleus: physiologic and histologic effects. Hearing Res. 2000; 149:223-238.

5. McCreery DB, Lossinsky A, Pikov V, Liu X. Microelectrode array for chronic deep-brain microstimulation and recording. IEEE Trans Biomed Eng. 2006; 53:726-737. [PubMed: 16602580]

6. Rizzo JF, Wyatt J, Loewenstein J, Kelly S, Shire D. Methods and perceptual thresholds for shortterm electrical stimulation of human retina with microelectrode arrays. Invest Ophthalmol Vis Sci. 2003; 44:5355-5361. [PubMed: 14638738]

7. Humayun MS, Weiland JD, Fujii GY, Greenberg R, Williamson R, Little J, Mech B, Cimmarusti V, Van Boemel G, Dagnelie G, de Juan E. Visual perception in a blind subject with a chronic microelectronic retinal prosthesis. Vision Res. 2003; 43:2573-2581. [PubMed: 13129543]

8. Mahadevappa M, Weiland JD, Yanai D, Fine I, Greenberg RJ, Humayun MS. Perceptual thresholds and electrode impedance in three retinal prosthesis subjects. IEEE Trans Neural Syst Rehabil Eng. 2005; 13:201-206. [PubMed: 16003900]

9. Palanker D, Vankov H, Huie P, Baccus S. Design of a high-resolution optoelectronic retinal prosthesis. J Neural Eng. 2005; 2:S105-S120. [PubMed: 15876646]

10. Robblee LS, Lefko JL, Brummer SB. Activated Ir: An electrode suitable for reversible charge injection in saline. J Electrochem Soc. 1983; 130:731-732.

11. Weiland JD, Anderson DJ, Humayun MS. In vitro electrical properties for iridium oxide versus titanium nitride stimulating electrodes. IEEE Trans Biomed Eng. 2002; 49:1574-1579. [PubMed: 12549739]

12. Wang K, Fishman HA, Dai H, Harris JS. Neural stimulation with a carbon nanotube microelectrode array. Nano Lett. 2006; 6:2043-2048. [PubMed: 16968023]

13. Ludwig KA, Uram JD, Yang J, Martin DC, Kipke DR. Chronic neural recordings using silicon microelectrode arrays electrochemically deposited with a poly(3,4-ethylenedioxythiophene) (PEDOT) film. J Neural Eng. 2006; 3:59-70. [PubMed: 16510943]

14. Zhou, DM. Platinum electrode and method of manufacturing the same. U.S. Patent. 6,974,533. 2005 Dec 13. 
15. Schmidt EM, Bak MJ, Hambrecht FT, Kufta CV, O'Rourke DK, Vallabhanath P. Feasibility of a visual prosthesis for the blind based on intracortical microstimulation of the visual cortex. Brain. 1996; 119:507-522. [PubMed: 8800945]

16. Hambrecht FT. Visual prostheses based on direct interfaces with the visual system. Baillieres Clin Neurol. 1996; 4:147-165. [PubMed: 7633780]

17. Cogan SF, Guzelian AA, Agnew WF, Yuen TG, McCreery DB. Over-pulsing degrades activated iridium oxide films used for intracortical neural stimulation. J Neurosci Methods. 2004; 137:141150. [PubMed: 15262054]

18. Meyer RD, Cogan SF, Nguyen TH, Rauh RD. Electrodeposited iridium oxide for neural stimulation and recording electrodes. IEEE Trans Neural Syst Rehabil Eng. 2001; 9:2-11. [PubMed: 11482359]

19. Robblee LS, Mangaudis MJ, Lasinsky ED, Kimball AG, Brummer SB. Charge injection properties of thermally-prepared iridium oxide films. Mat Res Soc Symp Proc. 1986; 56:303-310.

20. McIntyre JDE, Peck WF, Nakahara S. Oxidation state changes and structure of electrochromic iridium oxide films. J Electrochem Soc. 1980; 127:1264-1268.

21. Kang KS, Shay JL. Blue sputtered iridium oxide films (blue SIROF's). J Electrochem Soc. 1983; 30:766-769.

22. Klein JD, Clauson SL, Cogan SF. The influence of substrate bias on the morphology and charge capacity of RF-sputtered iridium oxide films. J Mater Res. 1989; 4:1505-1510.

23. Klein JD, Clauson SL, Cogan SF. Morphology and charge capacity of sputtered iridium oxide films. J Vac Sci Technol. 1989; A7:3043-3047.

24. Aurian-Blajeni B, Boucher MM, Kimball AG, Robblee LS. Physicochemical characterization of sputtered iridium oxide. J Mater Res. 1989; 4:440-446.

25. Slavcheva E, Vitushinsky R, Mokwa W, Schnakenberg U. Sputtered iridium oxide films as charge injection material for functionalized electrostimulation. J Electrochem Soc. 2004; 151:E226-E237.

26. Cogan SF, Plante TD, Ehrlich J. Sputtered iridium oxide films (SIROFs) for low-impedance neural stimulation and recording electrodes. Conf Proc IEEE Eng Med Biol Soc. 2004; 6:4153-4156. [PubMed: 17271216]

27. Wessling B, Mokwa W, Schnakenberg U. RF-sputtering of iridium oxide to be used as stimulation material in functional medical implants. J. Micromech. Microeng. 2006; 16:S142-S148.

28. Winter JO, Cogan SF, Rizzo JF. Neurotrophin-eluting hydrogel coatings for neural stimulating electrodes. J. Biomed. Mater. Res. B Appl. Biomater. 2007; 81:551-563. [PubMed: 17041927]

29. Klein JD, Clauson SL, Cogan SF. Reactive $\mathrm{IrO}_{2}$ sputtering in reducing/oxidizing atmospheres. J Mater Res. 1995; 10:328-333.

30. Selkurt, EE. Body water and electrolyte composition and their regulation. In: Selkurt, EE., editor. Physiology. Third Edition. Boston: Little, Brown \& Company; 1971. p. 529-534.

31. Cogan SF, Troyk PR, Plante TD, Ehrlich J, Detlefsen DE. Potential-biased, asymmetric waveforms for charge-injection with activated iridium oxide (AIROF) neural stimulation electrodes. IEEE Trans Biomed Eng. 2006; 53:327-332. [PubMed: 16485762]

32. Cogan SF, Troyk PR, Ehrlich J, Gasbarro CM, Plante TD. The influence of electrolyte composition on the in vitro charge-injection limits of activated iridium oxide (AIROF) stimulation electrodes. J Neural Eng. 2007; 4:79-86. [PubMed: 17409482]

33. Troyk PR, Detlefsen DE, Cogan SF, Ehrlich J, Bak M, McCreery DB, Bullara L, Schmidt E. "Safe" charge-injection waveforms for iridium oxide (AIROF) microelectrodes. Conf Proc IEEE Eng Med Biol Soc. 2004; 6:4141-4144. [PubMed: 17271213]

34. Beebe X, Rose TL. Charge Injection Limits of Activated Iridium Oxide Electrodes with $0.2 \mathrm{~ms}$ Pulses in Bicarbonate Buffered Saline. IEEE Trans Biomed Eng. 1988; 35:494-495. [PubMed: 3397105]

35. Rose TL, Robblee LS. Electrical stimulation with Pt electrodes. VIII. Electrochemically safe charge injection limits with 0.2 ms pulses. IEEE Trans Biomed Eng. 1990; 37:1118-1120. [PubMed: 2276759]

36. Tarlov MJ, Semancik S, Kreider KG. Mechanistic and response studies of iridium oxide $\mathrm{pH}$ sensors. Sensors and Actuators. 1990; B1:293-297. 
37. Bardin M, Loheac P, Petit M, Plichon V, Richard N. Electrochemical and mirage detection studies of sputtered iridium oxide films. New J. Chem. 1995; 19:59-63.

38. Pickup PG, Birss VI. Chemical analysis of the ionic content of hydrous iridium oxide films. J Electroanal Chem. 1988; 240:171-183. 


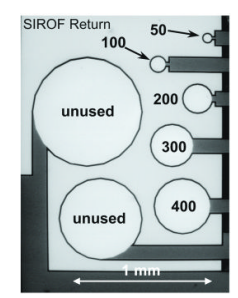

Figure 1.

SEM image of a 7-electrode cluster identifying the five electrode sizes (50-400 $\mu \mathrm{m}$ diameter) evaluated in the present study. The light areas in the image are SIROF. Two unused SIROF sites and the approximately rectangular unused SIROF return site surrounding the charge-injection electrodes, are also indicated. 


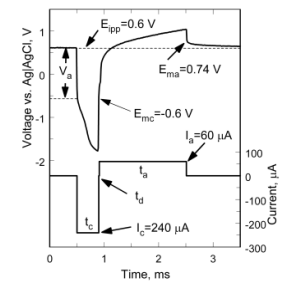

Figure 2.

Representative voltage transient of a SIROF electrode in response to a biphasic, asymmetric current pulse with a $240 \mu \mathrm{A}$ cathodal-first leading phase and a $60 \mu \mathrm{A}$ anodal phase $\left(\mathrm{t}_{\mathrm{c}}=0.4\right.$ $\left.\mathrm{ms}, \mathrm{t}_{\mathrm{a}}=1.6 \mathrm{~ms}, \mathrm{t}_{\mathrm{d}}=20 \mu \mathrm{s}\right)$. 


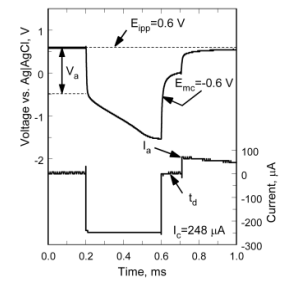

Figure 3.

Representative voltage transient of a SIROF electrode in response to a monophasic, $256 \mu \mathrm{A}$ cathodal current pulse (pulse width $=0.4 \mathrm{~ms})$ using a positive potential bias of $0.6 \mathrm{~V}(\mathrm{Ag}$ $\mathrm{AgCl})$. 


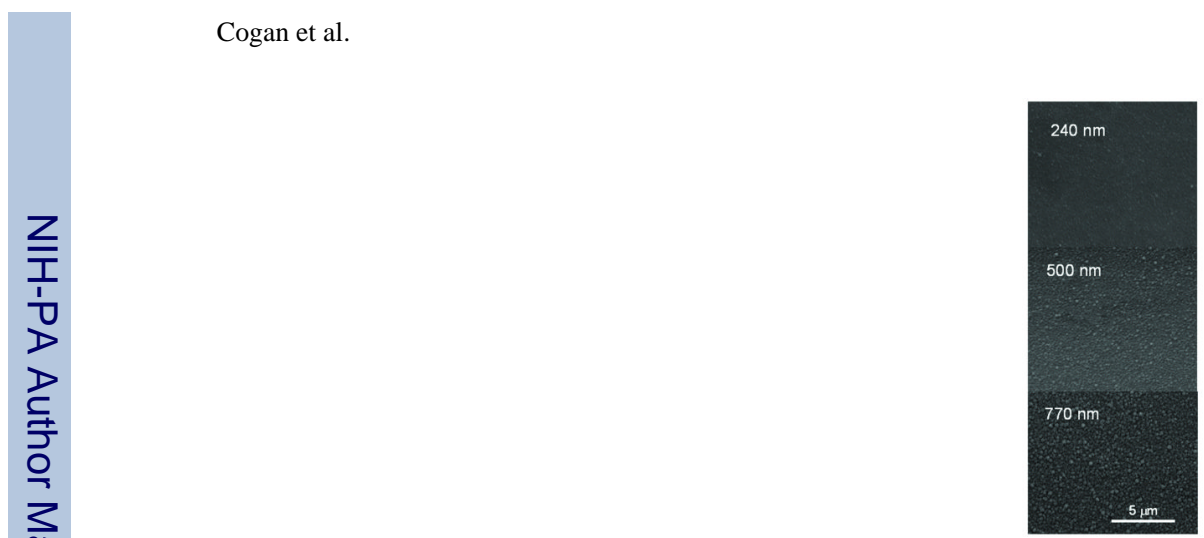

Figure 4.

SEM images of the surface morphology of $240 \mathrm{~nm}, 500 \mathrm{~nm}$, and $770 \mathrm{~nm}$ thick SIROF. 


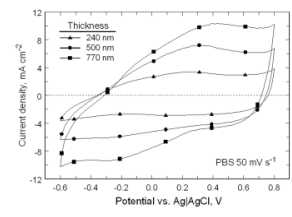

Figure 5.

Cyclic voltammograms of SIROF at $50 \mathrm{mV} / \mathrm{s}$ sweep rate in PBS as a function of thickness. The corresponding CSC ${ }_{\mathrm{c}}$ 's are $78 \mathrm{mC} / \mathrm{cm}^{2}(240 \mathrm{~nm}), 133 \mathrm{mC} / \mathrm{cm}^{2}(500 \mathrm{~nm})$ and $194 \mathrm{mC} /$ $\mathrm{cm}^{2}(770 \mathrm{~nm})$. 


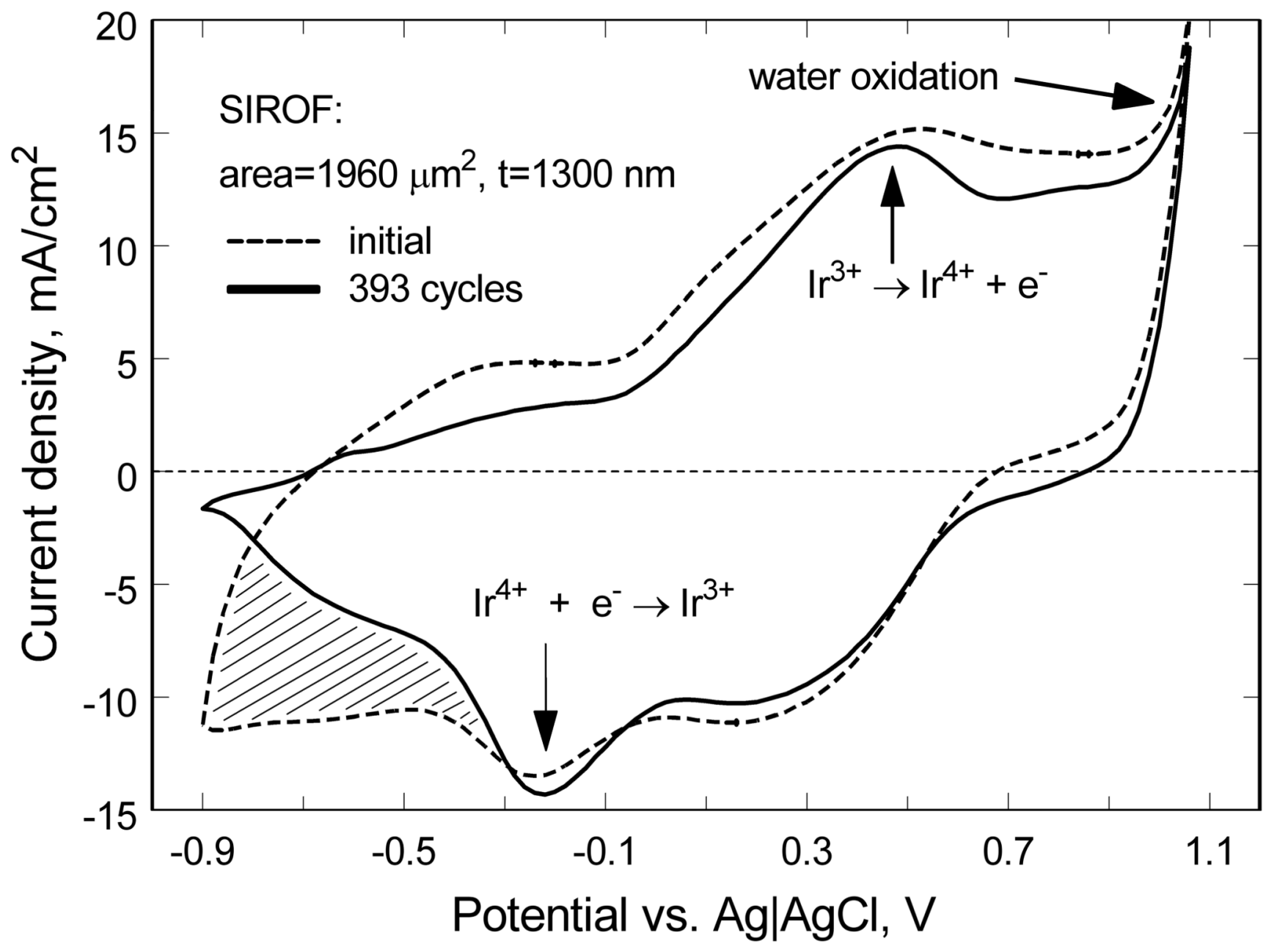

Figure 6.

Changes in the $\mathrm{CV}$ response of a $1300 \mathrm{~nm}$ thick SIROF after 393 cycles at $50 \mathrm{mV} / \mathrm{s}$ between $-0.9 \mathrm{~V}$ and $1.05 \mathrm{~V}$ vs. $\mathrm{Ag} \mid \mathrm{AgCl}$. 


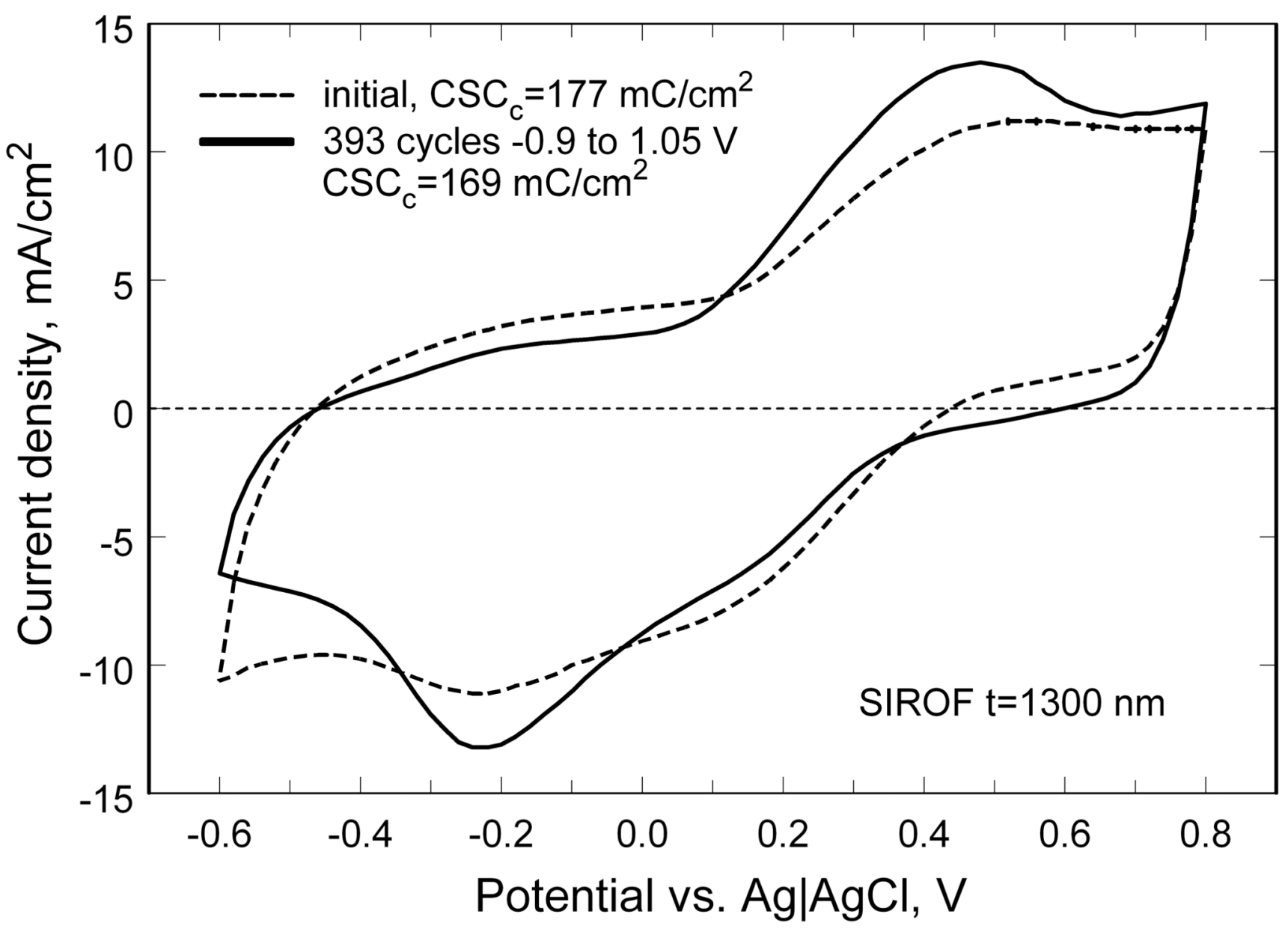

Figure 7.

Changes in the $\mathrm{CV}$ response of a $1300 \mathrm{~nm}$ thick SIROF after 393 cycles at $50 \mathrm{mV} / \mathrm{s}$ between $-0.6 \mathrm{~V}$ and $0.8 \mathrm{~V}$ vs. $\mathrm{Ag} \mid \mathrm{AgCl}$. 


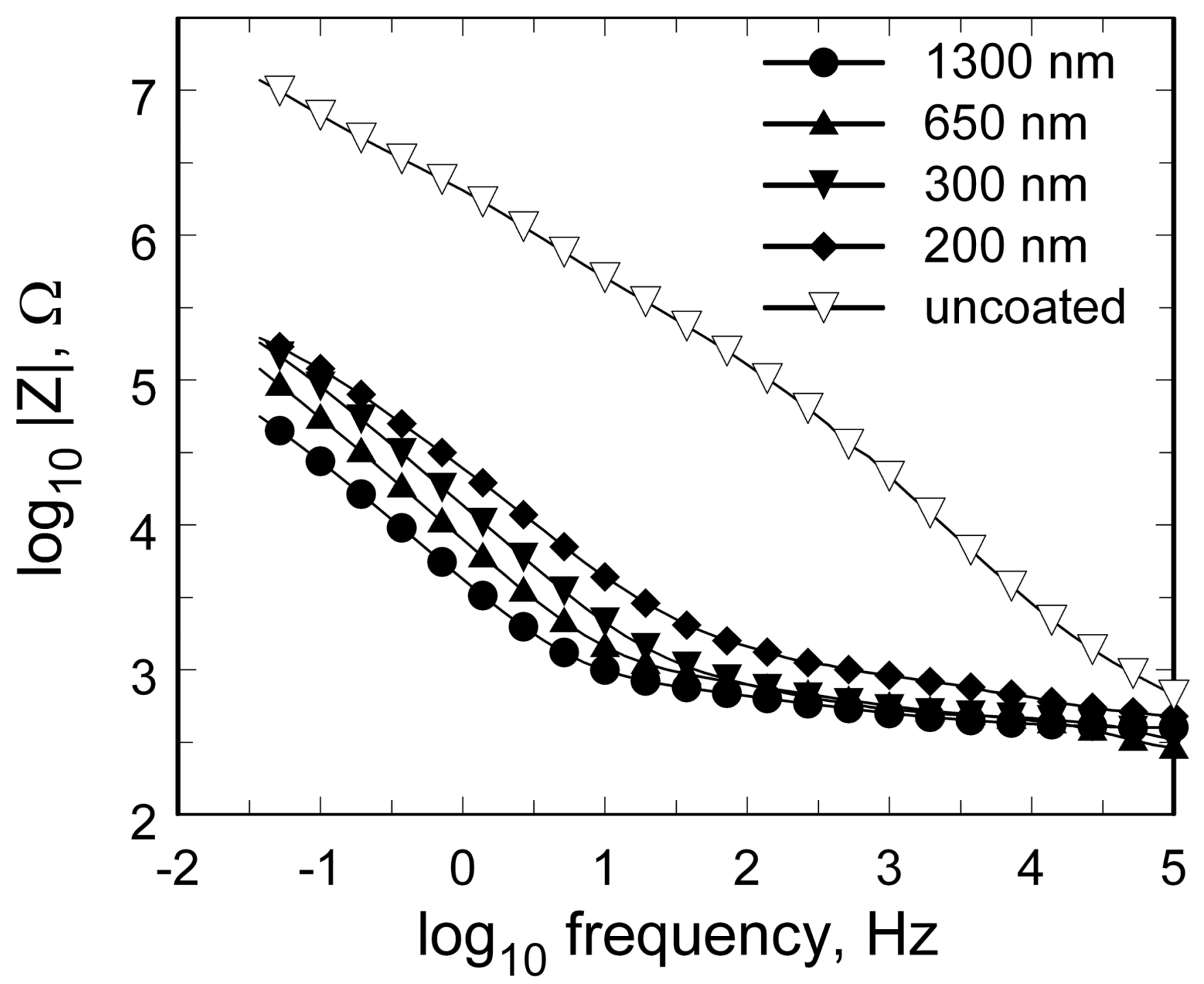

Figure 8.

Impedance magnitude as a function of frequency for 200-1300 nm thick SIROF. Each data point is the impedance averaged over potentials that were varied from $-0.6 \mathrm{~V}$ to $0.8 \mathrm{~V}(\mathrm{Ag} \mid$ $\mathrm{AgCl})$ in $0.1 \mathrm{~V}$ increments, with the vertical bars at each point representing the span of impedance. For clarity, only every fourth data point is indicated with a symbol. 


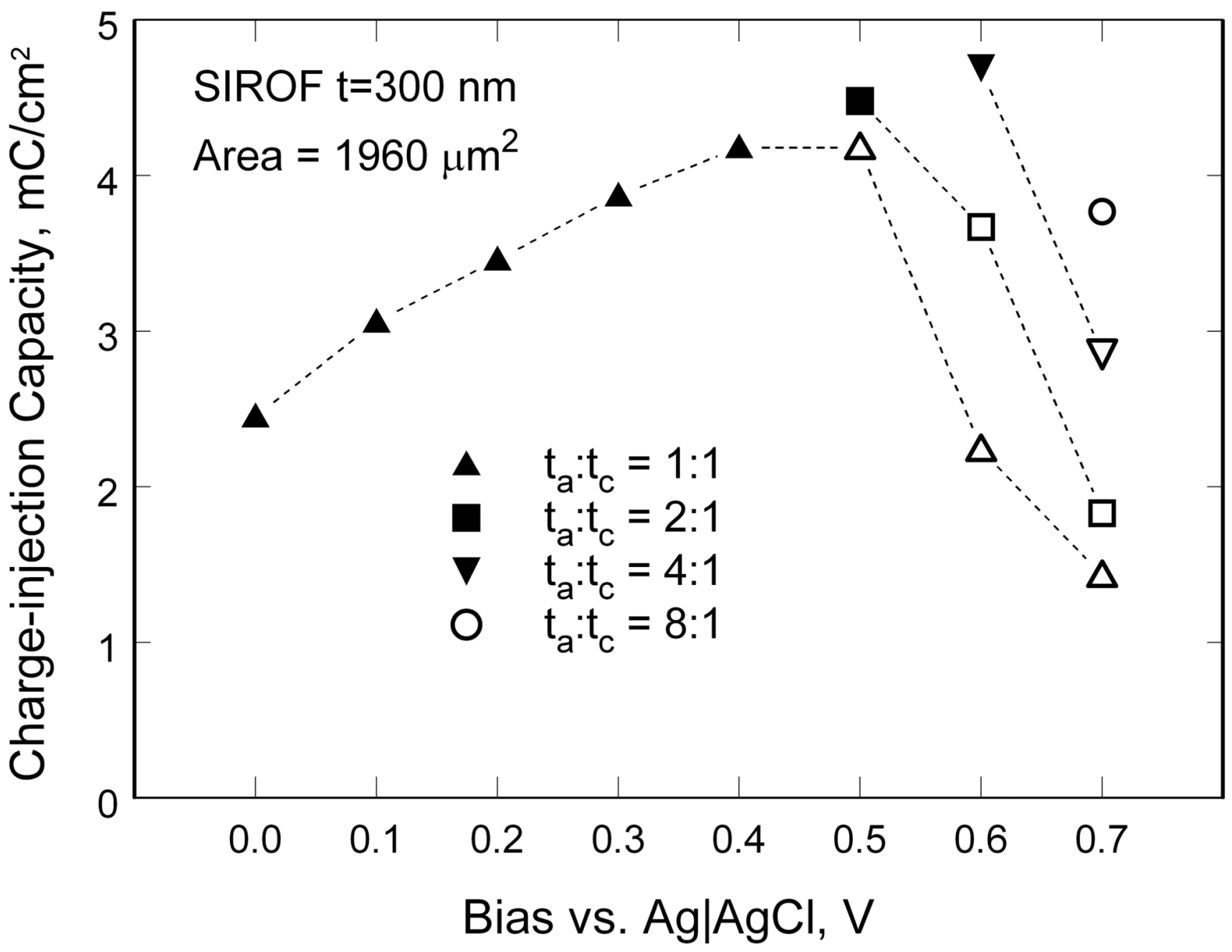

Figure 9.

Charge-injection capacity of a $300 \mathrm{~nm}$ SIROF in response to biased, biphasic asymmetric current pulses showing the dependence on bias level ( $E_{i p p}$ in Fig. 3) and waveform asymmetry $\left(\mathrm{t}_{\mathrm{a}}: \mathrm{t}_{\mathrm{c}}\right)$. Filled and open symbols represent cathodally and anodally limited charge-injection limits, respectively. 


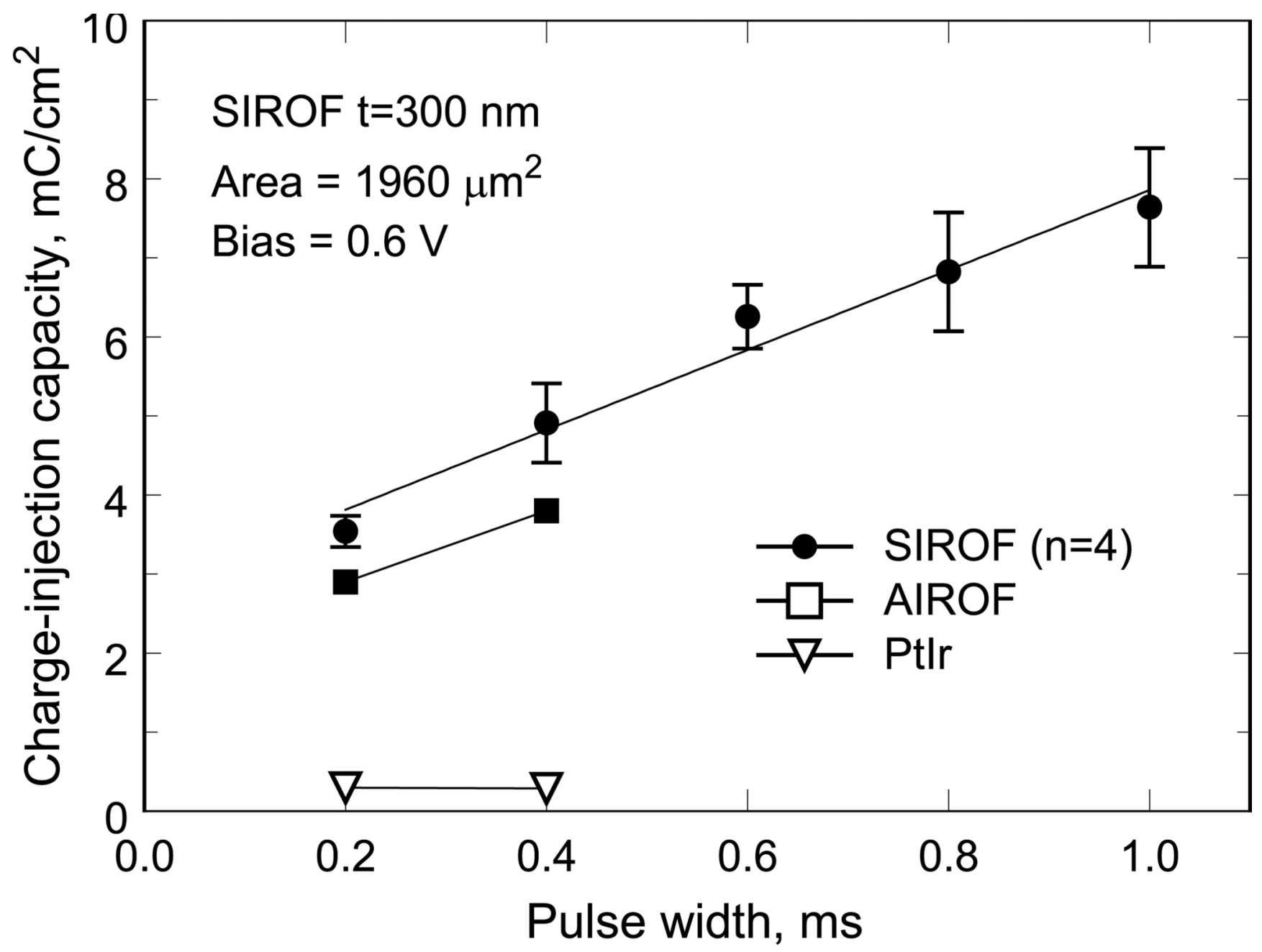

Figure 10.

Charge-injection capacity of a $300 \mathrm{~nm}$ SIROF as a function of pulse width. Similar sized AIROF and PtIr microelectrode data from Cogan et al2 are included for comparison. 


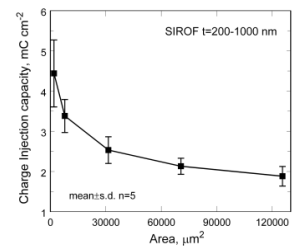

Figure 11.

SIROF charge-injection capacity as a function of electrode area. Each data point is the average of five thickness levels at each area (mean \pm sd). 


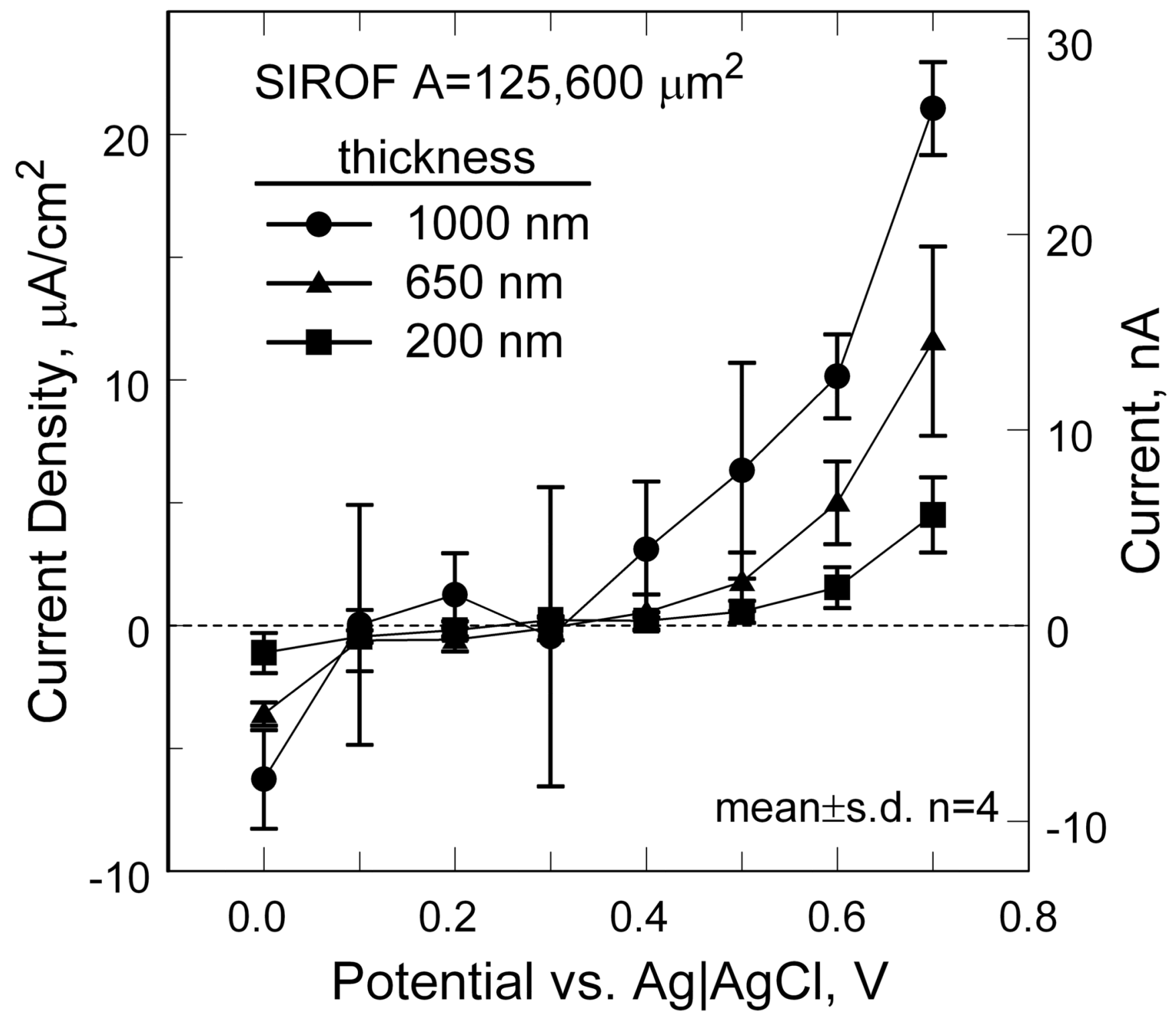

Figure 12.

Current necessary to sustain a non-equilibrium interpulse bias in model-ISF for three SIROF thickness levels. 